Paidéia, 2003, 12(24), 195-204

\title{
DEFICIÊNCIA AUDITIVA: ESCOLARIZAÇÃO E APRENDIZAGEM DE LÍNGUA DE SINAIS NA OPINIÃO DAS MÃES ${ }^{1}$
}

\author{
Eucia Beatriz Lopes Petean ${ }^{2}$ \\ FFCLRP - Universidade de São Paulo \\ Camila Dellatorre Borges \\ Prefeitura Municipal de São Simão
}

\begin{abstract}
RESUMO: A comunicação para a criança surda é essencial e conseqüentemente a aprendizagem da língua brasileira de sinais (LIBRAS). Com o objetivo de conhecer o processo de escolarização de surdos e a opinião das mães sobre a inclusão escolar e o aprendizado da LIBRAS, entrevistou-se dez mães de deficientes auditivos. Verificou-se que 6 crianças iniciaram sua escolarização antes dos 5 anos e todas freqüentaram ensino especial. As mães afirmaram que colocaram seus filhos na escola objetivando sua socialização e que são contra o aprendizado da língua de sinais, pois desejam que a criança aprenda a falar. A escolarização é considerada como importante, mas o ensino bilingüe não é aceito, demonstrando o desconhecimento destas mães em relação aos benefícios que este tipo de educação pode trazer para o desenvolvimento de seus filhos
\end{abstract}

Palavras-chave: deficiência auditiva; família; aprendizagem do LIBRAS

\section{AUDITIVE DEFICIENCY: SCHOOLING AND THE SIGNALS LANGUAGE LEARNING IN MOTHERS OPINION}

\begin{abstract}
Communication is essential for the deaf child and consequently the learning of the Brazilian signals language (LIBRAS). With the objective of knowing the process of deaf schooling and the opinion of mothers about the LIBRAS learning, ten mothers of auditive handicapped were interviewed. It was achieved that $60 \%$ of the deaf children started their schooling before 5 years old, all of them having attended special teaching. Mothers insert their children in school aiming their socialization and they are against the LIBRAS learning, since they expect the child to learn how to speak. Schooling is important but bilinguism is not accepted by mothers, reflecting the fact that these mothers ignore the benefits that this kind of education can bring to the development of their kids.
\end{abstract}

Key-words: auditive deficiency; family; LIBRAS learning

A linguagem, qualquer que seja ela, constituise talvez no principal meio pelo qual o homem se integra na sociedade. Através dela ele expressa suas idéias, opiniões, desejos e sentimentos. Segundo Capovilla (2000), é pela linguagem que a criança aprende sobre o mundo beneficiando-se da experiência vicária para além das meras imitações e observações diretas.

\footnotetext{
1 Artigo recebido para publicação em 10/2002; aceito em 12/2002

2 Endereço para correspondência: Eucia Beátriz Lopes Petean, Departamento de Psicologia e Educação, Faculdade de Filosofia, Ciências e Letras de Ribeirão Preto, USP, Rua XI de Agosto, 587, Campos Elíseos, Ribeirão Preto, SP, 14085-030, e-mail: ebpetean@ffclrp.usp.br
}

Assim, o déficit auditivo constitui-se em um fator importante, pois acarreta problemas que vão além do comprometimento de fala, percebendo-se atrasos no desenvolvimento cognitivo e social. Entretanto, de acordo com Santoro (1996), a surdez, mesmo afetando algumas experiências de vida, não limita a inteligência, a capacidade emocional ou o desenvolvimento e maturação normais. A autora salienta que a literatura encontra-se repleta de pesquisas apontando um atraso acadêmico, mas pondera que este pode decorrer não da capacidade intelectual do aluno, porém do seu desempenho lingüístico. Desse modo, observa-se que o desenvolvimento de uma criança surda é influenciado pelo acesso que 
possui aos meios pelos quais aprende a linguagem, seja ela falada ou não.

Por outro lado, a questão de comunicação para a criança surda tem sido ponto de controvérsia entre profissionais e pesquisadores, que se acham divididos em oralistas, que acreditam que independente do grau de deficit auditivo o surdo deve ser levado a falar e a desenvolver competência linguística oral e assim ser integrado ao mundo dos ouvintes e os bilingüístas que enfatizam a importância da comunicação seja ela oral ou não.

Para autores como Góes (1996) e Quadros (1997), a língua de sinais é considerada a natural dos surdos e deve ser aprendida. Neste sentido Góes (1996) salienta que "Sobretudo nas situações de surdez congênita ou precoce em que há problemas de acesso à linguagem falada, a incorporação de uma língua de sinais mostra-se necessária para que sejam configuradas condições mais propícias à expansão das relações interpessoais, que constituem o funcionamento nas esferas cognitiva e afetiva, e funda a construção da subjetividade" (p. 38).

Santoro (1996) afirma que os anos pré-escolares representam, psicológica, educacional e lingüisticamente, um período crucial da vida da criança surda e de sua família. Assim, um dos objetivos da escola seria o de proporcionar formas de estabelecer a competência em linguagem expressiva e receptiva o mais cedo possível.

Uma educação adaptada, utilizando diferentes recursos comunicativos que contribuam para a socialização do deficiente auditivo, deverá ter repercussões favoráveis na sua aprendizagem.

Contudo, segundo Souza (1995), o ensino bilíngüe implicaria na mudança de ideologia a respeito da surdez, mais do que na troca de uma metodologia por outra, ou seja, oralismo versos bilingüismo.

Também, para se adotar o bilingüismo é preciso que a família participe. $O$ acesso à educação tornou-se parte intrínseca da formação de um cidadão, contudo é longa a luta das pessoas deficientes pelo direito à inserção em um sistema educacional que lhes propicie um desenvolvimento pleno de suas potencialidades, tendo uma socialização sadia, e, como diz Marchezi (1995), que não as coloque à margem, seja do mundo dos ouvintes, seja do dos surdos. Nesse processo, tornar-se importantíssima a participa- ção da família, nãọ só como promotora do desenvolvimento, mas como agente mediador entre a escola e a sociedade. E, de acordo com Quadros (1997), ela deve conhecer a proposta para que possa se engajar adequadamente, já que ela é o grupo social primário a que a criança pertence, cabendo-lhe, portanto, as decisões sobre os atendimentos necessários, entre eles a escola.

Mais recentemente, a proposta de uma educação inclusiva veio tornar mais complexa e conflitante a decisão dos pais. Levar a criança para o ensino regular ou especial é uma das grandes dúvidas que se somam á de aderir ou não ao bilingüismo. $E$ importante que eles estejam corretamente informados sobre as necessidades educacionais do filho, os recursos disponíveis, bem como as vantagens e limites de cada um.

Nesse processo, Cárnio (1997) aponta como sendo responsabilidade dos profissionais informar ao surdo e a sua família sobre as possibilidades educacionais e modalidades de linguagem, de forma que possam realizar escolhas conscientes.

O presente trabalho se insere em uma linha mais ampla e pretendeu conhecer como foi o processo de escolarização de crianças surdas, alunos da rede pública de ensino de Ribeirão Preto e a opinião das mães sobre a inclusão escolar e o aprendizado da língua de sinais.

\section{Método}

\section{Participantes}

Participaram deste estudo dez mães de deficientes auditivos, de ambos os sexos, com idades entre 7 e 16 anos, que freqüentavam classe especial e/ou regular de instituições de ensino da rede municipal ou estadual da cidade de Ribeirão Preto-SP.

\section{Material}

Utilizou-se um roteiro de entrevista semiestruturado, feito de acordo com as normas da literatura e pré-testado (Bogdan \& Biklen,1994; Valles, 1997) cuja elaboração visou atender, especificamente, aos objetivos deste estudo. Foi usado gravador, fita cassete e material de secretaria. 


\section{Procedimento}

\section{Coleta dos Dados}

Para a seleção dos participantes, entrou-se inicialmente em contato com duas professoras de classes de crianças deficientes auditivas, uma de escola municipal outra da estadual. Após terem sido explicados os objetivos da pesquisa solicitou-se a elas que informassem as mães e pedissem sua colaboração. Fornecidos os nomes pelas professoras, fez-se o contato com as famílias e para aquelas que aceitaram participar foi assinado Termo de Consentimento Informado. Obteve-se, desse modo, uma amostra não-probabilista como definido por Laville e Dionne (1999).

As entrevistas foram gravadas e tiveram a duração média de quarenta e cinco minutos a uma hora e realizadas no local de preferência das mães.

\section{Análise de dados}

As entrevistas foram transcritas na integra. Realizou-se análise quantitativa, em termos de freqüência simples e porcentagem, para os dados referentes à idade de ingresso da criança na escola, ao número de instituições freqüentadas pela criança $\mathrm{e}$ às modalidades de atendimento escolar. Utilizou-se depois a Análise Temática de Conteúdo proposta por Minayo (1993) para os seguintes tópicos: motivos relatados pelas mães para a colocação e retirada do filho da escola, inclusão no ensino normal, aprendizado pela criança da língua dos sinais (LIBRAS) e justificativa para a realização do curso de LIBRAS. ${ }^{1}$



Gráfico 1 - Idade de ingresso da criança DA em instituições escolares

\section{Resultados e Discussão}

\section{O processo de Escolarização}

Pode-se observar no gráfico 1 que $30 \%$ das crianças deste estudo iniciaram sua escolarização aos três anos e $30 \%$ aos cinco, sendo que somente $10 \%$ da amostra começou escola precocemente, com um ano e meio de idade, frequientando creches, maternais ou berçários.

De acordo com Kirk e Gallagher (1987),

\footnotetext{
${ }^{1}$ Para evitar identificação, as entrevistas foram numeradas, os relatos designados por $\left(\mathrm{E}^{\circ}{ }^{\circ}\right)$ e o nome das crianças foi substituído por $\mathrm{N}$.
}

embora haja grande diversidade de estilos e de abordagens entre os educadores especializados em deficiência auditiva, todos concordam a respeito da importância de se iniciar o processo educacional cedo, e eles afirmam que qualquer que seja o programa, especial ou regular, ele é importante para o desenvolvimento das habilidades de comunicação e das atividades sociais. Se se entender por "cedo" a idade anterior aos sete anos, pode-se considerar que as crianças deste estudo iniciaram o processo de escolarização de acordo com o que preconiza a literatura; mas, se fosse admitido que só seria precoce se ela acontecesse desde os três anos, então, apenas uma das crianças deste estudo cumpriria o critério. 
Este fato leva a questionar se a informação sobre a importância do atendimento escolar precoce para o desenvolvimento da linguagem e socialização da criança com deficiência auditiva vem sendo efetiva e adequadamente oferecida às famílias que dela necessitam.

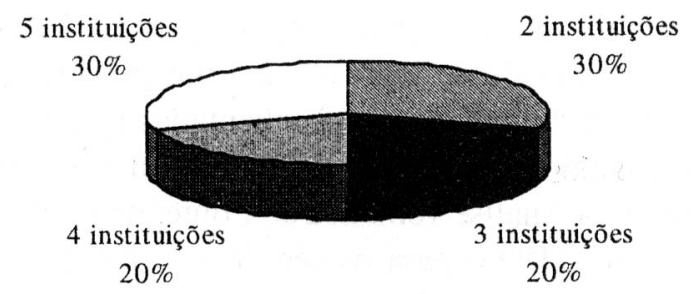

Gráfico 2. Número de instituições escolares freqüentadas

Em relação ao número de instituições escolares, de acordo com a figura 2 , as crianças deste estudo freqüentaram duas ou mais escolas até o momento, o que pode, talvez significar rotatividade por instituições. Mas, há que ter cuidado com este tipo de interpretação, uma vez que se tem sujeitos de 7 a 16 anos (Tab 1).

Também, este é um tema que merece discussão, pois a rotatividade pode ser causa e conseqüência do acesso dos deficientes a uma educação insatisfatória, advinda da atual condição da Educação Especial no Brasil e da dificuldade de aceitação e inclusão dos deficientes na sociedade. Fatores como o despreparo das instituições educacionais (regulares ou especializadas), de seus professores e da metodologia educacional inadequada favoreceria a troca frequiente, talvez gerando mais problemas, como a dificuldade de adaptação escolar e de formação de vínculos com os colegas e professores.

Tabela 1: Níveis de escolaridade freqüentadas por cada criança

\begin{tabular}{|c|c|c|c|c|c|c|c|c|c|c|c|}
\hline \multirow[t]{2}{*}{ Nível de escolaridade } & \multicolumn{11}{|c|}{ Crianças } \\
\hline & 1 & 2 & 3 & 4 & 5 & 6 & 7 & 8 & 9 & 10 & Total \\
\hline Nível pré-escolar (atendimento normal) & $\mathrm{X}$ & $\mathrm{X}$ & & $\mathrm{X}$ & & $\mathrm{X}$ & & & & & 4 \\
\hline Nível pré-escolar (atendimento especializado) & $\mathrm{X}$ & & $\mathrm{X}$ & $\mathrm{X}$ & & & $\mathrm{X}$ & & $\mathrm{X}$ & $\mathrm{X}$ & 6 \\
\hline Nível fundamental (atendimento normal) & $\mathrm{X}$ & $\mathrm{X}$ & $\mathrm{X}$ & $\mathrm{X}$ & $\mathrm{X}$ & $\mathrm{X}$ & & & & & 6 \\
\hline Nível fundamental (atendimento especializado) * & $\mathrm{X}$ & $\mathrm{X}$ & $\mathrm{X}$ & $\mathrm{X}$ & $\mathrm{X}$ & $\mathrm{X}$ & $\mathrm{X}$ & $\mathrm{X}$ & $\mathrm{X}$ & $\mathrm{X}$ & 10 \\
\hline Total & 4 & 3 & 3 & 4 & 2 & 3 & 2 & 1 & 2 & 2 & \\
\hline
\end{tabular}

Observa-se nos dados da tabela 1 que todas as crianças deste estudo, em algum momento de sua vida escolar, freqüentaram ensino especializado e que 6 delas cursaram ensino regular concomitante ou não.

$\mathrm{O}$ fato de algumas crianças estarem também participando do ensino regular demonstra já, de certa forma, o início de inserção destes deficientes auditivos. Omote (1999) pondera que, historicamente, os recursos da educação especial têm sido criticados como segregadores, porque utilizados como um freio para o percurso do deficiente à integração. Contudo, o autor ressalta que o caráter segregador ou integrador de uma instituição de ensino depende fundamentalmente de como o recurso (classe especial ou regular) é utilizado.

\section{Motivos Relatados pelas Mães para a Coloca- ção do Filho na Escola}

Os relatos apresentados pelas mães trazem conteúdos referentes à colocação do filho na escola e à decisão por uma ou outra, segundo os diferentes motivos.

1) Propiciar desenvolvimento social à criança “... eu pus ele no jardim. Isso pra incentivar, pra ele começar a ficar no meio de criança, para ele parar com aquele negócio de querer ficar só sozinho." (E2)

"Depois eu acabei passando ele para a escolona ... E a fono que falou para mim porque é bom para ele ter convivio." (E6)

2) Sugestão de profissionais especializados "A professora falou que seria melhor colocar na classe especial, ela não está acompanhando. Ai foi quando eu procurei, tinha a escola 1 e a escola 2 ..." (E4) 
"Os médicos da época falaram que não era colocar ela em escola especial, que ela iria bem numa escola normal .... E na $5^{\circ \circ}$ série a professora dela indicou a escola 3 que tinha a classe especial." (E5)

\section{3) Outros motivos}

"E ela via a irmã ir para a escolinha, ela pegava a mochila e queria ir atrás, então eu conversei com a professora e com a diretora e coloquei ela numa escolinha particular." (E1)

"O meu cunhado falou que na $3^{\circ \circ}$ série se eu quisesse ele poderia tentar levar lá ... $e$ a gente ficava com medo que alguém batesse, que judiasse dela ou que batessem no aparelho dela ... Ele ia junto, cuidava dela pra mim no intervalo." (E5)

Pode-se constatar que para algumas mães a decisão de colocar o filho na escola foi considerada como um recurso para promover a socialização. $\mathrm{Na}$ opinião delas a orientação dos profissionais sobre colocar a criança na escola e em que modalidade de ensino fazê-lo é muito importante.

Carnio (1997) ressalta exatamente esse papel de orientadores dos profissionais. $\mathrm{O}$ mesmo faz Glat (1996) enfatizando que o especialista, entre outras atribuições, detém o monopólio das comunicações para o deficiente, sendo considerado o responsável pelo desenvolvimento e implementação das chamadas propostas de integração.

Nesta pesquisa observou-se, contudo, que os profissionais apenas sugeriram instituições, não esclarecendo as características, potencialidades ou limites delas bem como suas propostas educacionais. Nesse sentido, Manzini (1989) relata que os profissionais encaminham com freqüência para serviços segregativos, sem contudo fazer menção, para a família, do problema do estigma que uma instituição especializada pode acarretar ao indivíduo. Soma-se a esse posicionamento a questão de que muitos deles desconhecem ou possuem preconceitos quanto às reais potencialidades da criança, bem como das instituições educacionais.
Lora (1984) já alertava para este fato, admitindo ser frequiente que os profissionais que atuam com deficiência reproduzirem estigmas para as famílias, não informando e nem orientando de maneira clara, o que não favorece e até mesmo dificulta maior compromisso dos pais com a escolarização do filho.

Uma nova conduta dos profissionais deveria ser pautada na sua conscientização de sua função enquanto ponto de referência e orientação; mas, de acordo com Regen (1997) eles mostram resistências em adotar esse papel, pois temem perder o poder sobre seus clientes.

Outro tema que aparece nesta questão da inserção do deficiente auditivo na escola é a necessidade que os pais manifestam de se assegurarem de que o filho não sofrerá agressões. Essa preocupação também foi observada no estudo de Batista \& Silva (1996) e uma explicação possível para ela talvez esteja na crença de que a própria criança não sabe se defender, tanto em função da dificuldade de comunicação com os demais, quanto do contato social com o meio, gerando assim uma conduta superprotetora dos pais.

\section{Motivos Relatados pelas Mães para a Retirada do Filho de uma Escola}

1) Inadequação do ambiente escolar

\begin{abstract}
"Não fiquei muito tempo lá não. Porque estava com aquele problema de troca de diretora, troca de funcionário, troca de governo. Aí começou a ficar muito confuso o negócio lá ... Aí colocaram ela na classe especial da escola 3, só que a classe da escola 3, eu não sei se estou errada, tem criança de 7 , tem criança de 10 , tem criança de 12, tem criança de15, tem criança de 16 , tem criança de 17 ... enquanto um está chupando pirulito o outro está falando de sexo. Não sei como é que fica a cabeça dessa criança." (E1)
\end{abstract}

"Fez o primeiro ano e não conseguiu passar, aí ia fazer o primeiro ano de novo, co- 
meçou mas aí a professora falou que seria melhor colocar na classe especial, ela não está acompanhando." (E4)

2) Inadequação do professor e da metodologia educacional

3)

"Aí eu senti que estava uma criança excluida, uma criança que o professor não está nem aí. E o dia que queria pegava e o dia que não queria tocava o bonde do jeito que tocava." (E1)

“... ela (a professora) falou pra mim ‘ Se a senhora quiser deixar ele lá, ele pode ficar, só que ele vai ficar lá, eu não vou ter condição de dar atenção a ele como eu vou dar para os outros que já sabem ler e escrever'." (E8)

"Apesar que quando ela estava lá na instituição 2, uma mulher falou que lá ela iria aprender a usar os sinais e que ela não ia ensinar a fala. Aí eu tirei ela ..." (E4)

4) Recusa da criança ir à escola

5)

"O ano passado eu tentei por ele na $l^{\circ}{ }^{\circ}$ série, mas ele não quis ir porque os meninos eram pequenininhos." (E8)

"Aí ele não queria ir não. Porque uma classe cheia de gente e ninguém entendia ele, ele não entendia ninguém, não tinha nenhum coleguinha." (E10)

A inadequação do ambiente escolar é apresentado pelas mães como fator preponderante para a retirada da criança da escola, caracterizada através da alta rotatividade de funcionários, da conduta dos professores que não atendem às suas expectativas. A escola é então percebida como não oferecendo um ensino que permita o acompanhamento e, conseqüentemente, o desenvolvimento da criança surda.

Estes dados assemelham-se aos de Omote (1996) e Nunes (1998) que também afirmam que a rotatividade de profissionais e da equipe técnica con- tribui para que os serviços oferecidos não tenham continuidade, não atendendo às necessidades cotidianas das famílias e dificultando a relação pais -serviços da comunidade.

Um fato importante a ser salientado está na sugestão do profissional que indica que a criança deveria deixar a escola ou trocar de sala, tendo como justificativa a sua não "condição" em freqüentar aquele nível educacional. Manzini (1989), em seu estudo sobre a segregação/integração de um indivíduo deficiente físico em uma instituição escolar, também relatou atitude semelhante da professora, que foca o problema na criança, retirando da escola qualquer parcela de responsabilidade no atendimento educacional ao deficiente.

A presença de prática segregacionista por parte dos profissionais da escola, em relação à educação dos portadores de deficiência, contrariando os preceitos da integração, foi constatada por Nunes et al (1998), cujo estudo apontou que os professores das classes regulares, muitas vezes, rejeitavam a proposta de integração por acreditarem que não possuíam condições concretas e subjetivas para terem uma atuação adequada com o deficiente.

Vários seriam os fatores que produzem a falta de suporte e a incapacidade do sistema educacional em incorporar e educar adequadamente crianças com deficiência, fazendo com que elas sejam induzidas a trocar de instituição, livrando-se assim do problema: a) Falha na comunicação entre profissionais, professor de classe regular e classe especial; b) despreparo emocional e metodológico dos professores no manejo do ensino em sala de aula em que há criança com necessidades especiais; c) preconceitos dos profissionais em relação à criança deficiente auditivo por desconhecerem suas necessidades, potencialidades e limites.

Todos estes pontos estão associados a um sentimento de desajuste do deficiente em relação ao grupo de pares, provocado tanto por diferença de idade em relação aos colegas de sala, quanto por sua dificuldade de comunicação e socialização, e podem vir a se concretizar na recusa em permanecer na escola.

\section{Opinião das Mães sobre Inclusão Escolar}

Os relatos expressam basicamente dois conteúdos que refletem a descrença das mães no processo de inclusão. 
1) Professor despreparado

"Sou contra porque os professores não estão preparados. $O$ professor acha que é um joão-ninguém ali no canto. Ele vai acompanhar até o dia em que a criança acompanhar, o dia que a criança não acompanhar ela vai ficar de novo e vai ficar aí... Então é uma coisa que não vai dar certo, já tive experiência

2) Inadaptação da criança ao ensino regular

"Não que a gente queira discriminar que o filho da gente seja separado, mas essas crianças não tem condição de ir para uma escola normal. Essas crianças tem que ir para uma escola separada." (EI)

A descrença no processo de inclusão é justificada aqui pelo despreparo dos professores e do próprio ensino regular para receber esta clientela, refletindo na maneira como a criança seria tratada, criando a possibilidade de rejeição e abandono.

Parece existir um consenso de que, na atual condição da Educação, os professores da rede normal não apresentam preparo teórico e metodológico para receberem, em suas salas, crianças deficientes, o que poderia advir de despreparo profissional, como de condições inadequadas, que se pode começar a enumerar: 1- salas superlotadas; 2 - ausência de uma equipe que dê suporte; 3- preconceito e desconsideração com os alunos deficientes.

Macedo (2002) comenta esta questão afirmando que a educação inclusiva veio tornar a tarefa dos professores mais complexa e desafiadora, com implicações inclusive na direção de serem aprendidas outras técnicas e revistas as expectativas.

Omote (1999) analisa o problema por um outro ângulo e ressalta que não é qualquer aluno que pode freqüentar a classe de ensino comum, devendo-se ter critérios para tal. Ele pondera, também, que uma atitude precipitada pode resultar em maior segregação, já que o aluno deficiente iria competir com seus pares não deficientes em condições de extrema desigualdade, arriscando-se a favorecer o desenvolvimento de baixa auto-estima. Assim, a inserção em classes regulares distorceria a sua finalidade e comprometeria sua eficácia. Para evitar isto, seria ne- cessário que os pais e alunos deficientes estejam preparados para a situação do ensino inclusivo, pois esta pode parecer-lhes menos acolhedora que a do ensino especial.

A inclusão deve ser feita com critérios, focalizando tanto as competências e capacidades da criança, quanto o preparo e receptividade da escola como um todo, envolvendo assim desde o diretor, técnicos, professores, espaço físico, material pedagógico, metodologia de ensino até as condições e expectativas da família.

\section{Aprendizado e Utilização pela Criança da Lín- gua dos Sinais (Libras)}

1) Contra

"Eu sempre proibi ela de fazer gesto, porque se ela fala não precisa fazer gesto. Ai ela falava errado e eu batia de frente, sempre treinando para que ela falasse.." (E3)

"Apesar que quando ela estava lá na instituição 1, uma mulher falou que lá ela iria aprender a usar os sinais e que ela (a professora) não ia ensinar a fala. Aí eu tirei ela ... Porque em vez dela melhorar ela já estava falando tudo, ela ia usar só o sinal. Eu não queria isso. Ela podia até fazer mas eu queria que ela aprendesse a falar. Ai eu tirei de lá, porque se for só por sinal não vai dar." (E4)

- $N$ não é para você fazer gesto, é só fala. Você sabe falar.. Porque o meu medo é ele parar de falar" (E6)

"Eu falei : '_Não, se ela escuta, então ela vai ter que aprender a falar, tem que soltar a voz dela' ... Então ela tem que falar, porque se não se ela aniquilar naquilo só de sinal, ela não vai querer falar nunca." (E7)

"Não faço gesto de nada, eu faço ele falar.." (E8)

2) A favor

"Tem dia que ela senta e fica fazendo teste comigo pra ver se eu lembro dos gestos. Ela faz o gesto e quer que eu falo o quê que é. Ela manipula bastante coisas. 
Tem dia que a gente senta ali à tarde $e$ fica, quando não, ela fala a palavra $e$ pedi pra mim fazer o gesto." (E1)

"Com oito anos, quando elas viram que ele não ia mais, que não adiantava mais, então elas falaram pra mim que elas iam tentar com sinal. Eu falei: '_Não, pode fazer. Por mim tudo bem'...Lá na instituição, a professora conversava tudo com sinal." (E10)

Observa-se uma forte oposição ou mesmo proibição das mães no aprendizado e utilização da língua de sinais pela criança, sendo desejo delas que seus filhos aprendam a falar. Esse posicionamento é fundamentado na crença de que, se a criança aprender e utilizar a língua dos sinais, ela não irá desenvolver a fala ou mesmo querer isto, o que conseqüentemente dificultará sua comunicação e integração social.

O não desenvolvimento da fala parece atemorizar muito as mães, levando-as a condutas rígidas contra o aprendizado da LIBRAS, realizando um movimento de delimitação de espaços, antagonizando escola e casa, demarcando que em família os filhos apenas terão contato com a linguagem oral, numa tentativa explícita de controle do aprendizado da língua dos sinais. Atitude semelhante foi encontrada por Cárnio (1997) em seu estudo, tendo verificado que em suas residências muitos pais e familiares não permitem a utilização da língua de sinais.

Zepellini et al. (1991) e Santoro (1996) também assinalam que os pais têm grandes expectativas e forte desejo de que as crianças aprendam a linguagem oral.

Para Souza (1995) a crença de que se a criança aprender a língua dos sinais não desenvolverá a fala é partilhada por pais e pelos próprios profissionais especializados, sendo um mito sustentado pela posição audista que se vale de teorizações médicobiológicas sobre a inferioridade (pseudo) dos surdos. Supõe-se que o audismo fundamente a postura apresentada pelas mães participantes deste estudo e que elas tenham entrado em contato com essa concepção através das orientações recebidas dos profissionais especializados.

Embora a maioria das mães participantes da pesquisa sejam contrárias à aprendizagem da LIBRAS para seus filhos, elas estão cientes de que isto acontece no contato com os colegas e/ou nas próprias instituições escolares.

Okssar (1990) fala da importância da educação bilingüe na aquisição espontânea da linguagem, no desenvolvimento adequado de competência lingüística e de regras lingüísticas.

De acordo com Souza (1995) os pais devem ter clara consciência ao optarem por um ensino bilingüe, o que não significa que eles serão obrigados a se comunicar utilizando a linguagem dos sinais, pois, como em qualquer meio social, haverá provavelmente situações de mescla, mecanismos de ajustes discursivos ou de eleição de um sistema em detrimento de outro.

Ao refletir-se sobre os dados aqui apresentados, levanta-se a questão de que as mães/familiares sabem da existência da língua dos sinais, mas, por preconceito ou por desconhecerem o seu papel e sua eficácia na comunicação e desenvolvimento da criança, não se interessam em fazer com que ela a aprenda.

\section{Interesse das Mães no aprendizado da LIBRAS}

$O$ desejo e o interesse em realizarem o curso de LIBRAS estão inseridos numa busca pela mãe de maiores esclarecimentos e recursos para o entendimento e melhor adequação em lidar com o filho.

"Eu sempre procurei recursos, sempre procurei ajuda pra poder aprender. Eu faço cursos, eu pego apostila, eu compro livro mesmo que não leia ... Fiz um curso de gestos." (EI)

Por outro lado, quandó não há tal interesse, isto é justificado pela crença de que o aprendizado da língua de sinais seria difícil e que se a criança se comunicar pela língua dos sinais, ela não vai querer falar. Assim, a mãe não aprenderia para não contribuir com algo que considera inadequado.

"Não. Eu nunca fui atrás, porque eu acho muito difícil. ... Não vou aprender isso nunca'. Eu acho muito difícil demais... Se ela aniquilar naquilo só de sinal, ela não vai querer falar nun- 
ca, então eu nunca fui aprender isso... Eu não vou aprender isso não, nossa senhora. É muito complicado." (E7)

Quadros (1997) e Ferreira Brito (1993) salientam que os pais de crianças surdas deveriam aprender este método para interagir com o filho com mais eficiência.

Entretanto, fica evidente, pelos dados aqui apresentados, que a crença de que a criança não venha a falar se aprender a língua de sinas é tão forte que impede os pais de conhecerem os benefícios que este recurso traria para o desenvolvimento geral de seus filhos.

\section{Conclusão}

O presente estudo buscou conhecer parte do processo de escolarizáção de deficientes auditivos, a opinião das mães sobre a inclusão escolar e o aprendizado de LIBRAS.

Os resultados mostram que a escolarização dos deficientes auditivos acontece entre três e cinco anos de idade, sendo caracterizado por rotatividade pelas instituições escolares onde o ensino especial se constitui no recurso educacional mais utilizado por eles, objetivando promover a sua socialização através do aprendizado da linguagem oral.

Já o processo de inclusão escolar é visto com reserva pelas mães que apontam o despreparo dos professores e das escolas para promoverem o atendimento adequado a esta clientela.

Há uma forte oposição em relação à aprendizagem da LIBRAS ,expresso no desejo de que aprendam a linguagem oral. Fica evidente pela fala das mães o seu desconhecimento do papel que a língua de sinais representa no desenvolvimento cognitivo e afetivo da criança e na construção de sua subjetividade, e mesmo da importância da metodologia utilizada nas instituições de ensino. Elas não consideram a língua de sinais como natural e que facilitaria o desenvolvimento cognitivo dos deficientes auditivos.

Pergunta-se se as mães, ao desconsideram a língua dos sinais, não estariam criando mais entraves a uma evolução de seus filhos, o que corrobora com dados da literatura: elaboração conceitual rudimentar, baixa sociabilidade, rigidez e imaturidade emoci- onal, mesmo afirmando que não seria apenas a conduta das mães/familiares a responsável por esses comportamentos. A sociedade, também, colabora no processo de exclusão deste segmento da população.

Este estudo põe em evidência a necessidade de pesquisas mais aprofundadas na área, bem como de programas de intervenção visando o esclarecimento das famílias de deficientes auditivos no que diz respeito à importância da comunicação seja ela verbal ou gestual, para o desenvolvimento global desta população.

\section{Referências Bibliográficas}

Batista, C.G. \& Silva, A.B.P. (1996). O ingresso da criança surda na escola de primeiro grau - concepções e expectativas de pais e profissionais. Estudos de Psicologia, v.13, n.2, p.29-35.

Bogdan, R.C. \& Biklen, S.R. (1994). Investigação Qualitativa em Educação. Uma introdução à teoria e aos métodos. Porto: Porto Editora Ltda.

Cárnio, M.S. (1997). O surdo e o contexto educacional. In: I. Lichtig \& R.M.M. Carvalho (Orgs.) Audição: abordagens atuais (pp. 290-303). Carapicuíba: Pró-fono.

Capovilla, F.C. (2000). Filosofias educacionais em relação ao surdo: do oralismo à comunicação total ao bilinguismo. Revista Brasileira de Educação Especial. v.1, n6.

Ferreira Brito, L. (1993). Integração social e educação dos surdos. Rio de Janeiro: Babel.

Glat, R. (1996). O papel da família na integração do portador de deficiência. Revista Brasileira de Educação Especial, 2(4), p. 111-118.

Góes, M.C.R. (1996). Linguagem, surdez e educação. Campinas: Autores Associados.

Kirk, S.A. \& Gallagher, J.J. (1987). Educação da criança excepcional. São Paulo: Martins Fontes.

Laville, C. \& Dionne, J. (1999). A construção do saber: manual de metodologia da pesquisa em ciências humanas. Porto Alegre: Artes Médicas 
Lora, A.B. (1984). A família orientada como condição básica para o desenvolvimento da criança portadora de deficiência auditiva. Dissertação de Mestrado, São Paulo:Pontifícia Universidade Católica de São Paulo

Macedo, L. (2002). Fundamentos para uma Educação Inclusiva.. Site Educação On-Line. São Paulo. SP

Manzini, E.J. (1989). Segregação e integração do indivíduo deficiente físico: depoimento de uma mãe sobre a realidade educacional concreta. Didática, 25, p. 139-152.

Marchesi, A. (1995). Comunicação, linguagem e pensamento das crianças surdas. Em C. Coll, J. Palacios \& A. Marchesi (Orgs) Desenvolvimento psicológico e educação: necessidades educativas especiais e aprendizagem escolar (pp. 200-214). Porto Alegre: Artes Médicas.

Minayo, M.C.S. (1993). O desafio do conhecimento: pesquisa qualitativa em saúde. São Paulo: Hucitec.

Nunes, L.R.D., Glat, R., Ferreira, J.R. \& Mendes, E.G. (1998). Pesquisa em educação especial na pós-graduação. Rio de Janeiro: Viveiros de Castro (série Questões atuais em educação especial)

Omote, S. (1996). Conclusões do grupo de trabalho (GT3): A família do deficiente.Em: C. GOYOS; M.A. ALMEIDA \& D. SOUZA (Orgs) Temas em Educação Especial (pp. 516-525). São Carlos: EDUSCar.

Omote, S. (1999). Normalização, integração, inclusão. Ponto de Vista, 1(1), p. 4-13.

Quadros, R.M. (1997). Educação de surdos: a aquisição da linguagem. Porto Alegre: Artes Médicas.

Regen, M. (1997). Da segregação à integração: minha trajetória. In: M.T.E. Mantoan (Org.) $A$ integração de pessoas com deficiência: contribuições para uma reflexão sobre o tema (pp. 142-148) São Paulo: Memnon.
Santoro, B.M.R. (1996). Contando histórias, programando o ensino: a literatura na pré-escola com alunos surdos. Campinas: PUCCAMP.

Souza, R.M. (1995). Educação Especial, psicologia dos surdos e bilingüismo: bases históricas e perspectivas atuais. Temas em Psicologia, 2, p. 71 87.

Valles, M.S. (1997). Tecnicas Cualitativas de Investigación Social. Reflexion metodologica y pratica profissional. Madri: Editorial Sintesis, S.A.

Zepellini, S.L., Bonnafé, M.C. \& Pfeifer, E. (1991). Projeto 'Orientação à família da pessoa portadora de deficiência auditiva'. Pró-fono, 3, p. 8-13. 